\title{
Sensorless Control of Nonsinusoidal Permanent Magnet Brushless Motor Using Selective Torque Harmonic Elimination Control Method Based on Full-Order Sliding Mode Observer
}

\author{
Abolfazl Halvaei Niasar, ${ }^{1}$ Marzieh Ahmadi, ${ }^{2}$ and Sayyed Hossein Edjtahed ${ }^{1}$ \\ ${ }^{1}$ Department of Electrical \& Computer Engineering, University of Kashan, Kashan, Iran \\ ${ }^{2}$ Department of Electrical \& Computer Engineering, Islamic Azad University of Dolatabad, Dolatabad, Iran \\ Correspondence should be addressed to Abolfazl Halvaei Niasar; halvaei@kashanu.ac.ir
}

Received 22 June 2016; Accepted 2 November 2016

Academic Editor: Antonio J. Marques Cardoso

Copyright (C) 2016 Abolfazl Halvaei Niasar et al. This is an open access article distributed under the Creative Commons Attribution License, which permits unrestricted use, distribution, and reproduction in any medium, provided the original work is properly cited.

\begin{abstract}
Nowadays, due to excellent advantages of permanent magnet brushless (PMBL) motors such as high efficiency and high torque/power density, they are used in many industrial and variable-speed electrical drives applications. If the fabricated PMBL motor has neither ideal sinusoidal nor ideal trapezoidal back-EMF voltages, it is named nonideal (or nonsinusoidal) PMBL motor. Employing conventional control strategies of PMSMs and BLDCMs lowers the efficiency and leads to unwanted torque ripple, vibration, and acoustic noises. Moreover, in many applications to reduce the cost and enhance the reliability of drive, sensorless control techniques are used. This paper proposes a novel sensorless control for a nonsinusoidal PMBL motor with minimum torque ripple. To develop smooth torque, the selected torque harmonic elimination strategy is employed. Furthermore, to estimate the rotor position and speed, a novel full-order sliding mode observer is designed. Proposed observer estimates the position and speed of motor from standstill to final speed. The proposed observer is robust to uncertainty of harmonic contents in phase back-EMF voltage and able to run the motor from standstill with closed-loop control scheme. The capabilities of torque ripple minimization and sensorless strategies are demonstrated with some simulations.
\end{abstract}

\section{Introduction}

In two past decades and with reducing the price of permanent magnets material, design and manufacture of permanent magnet brushless (PMBL) motors have developed in industrial and nonindustrial different applications. Superior features such as high efficiency, high power and torque density, low maintenance cost, simple structure, and ease of control are the reasons for tendency to these motors. Due to mentioned reasons, PMBL motors are considered in high performance and accurate applications as electric transportation and aerospace and military industries or even newly in domestic and consumer applications [1].

The PMBL motors include two main categories of $\mathrm{AC}$ brushless (PMSM or BLAC) and DC brushless (BLDC) depending on the shape of phase back-EMF voltage of motor (sinusoidal or trapezoidal). The induced back-EMF voltages in stator windings of PMSMs are quite sinusoidal, whereas for BLDCMs they are trapezoidal waveforms with flat portion over a range of 120 degrees as shown in Figures 1(a) and 1(b). This difference is due to type of stator windings that in PMSM motor is sinusoidally distributed, whereas in BLDC motor it is distributed as uniform or centralized distribution [2, 3]. The difference of back-EMF voltage waveforms causes the employed control methods to be so different [4].

To develop constant instantaneous torque for PMSMs, vector based control such as field oriented control (FOC) or direct torque control (DTC) in two-axis reference frames is usually used. But for BLDCMs using of vector based methods is not common and their utilization leads to lots of torque ripple. Therefore, simple quasi-square (six-step) current methods are employed. The main advantages of six-step current methods for BLDCMs are hardware/software simplicity and ease of implementation as same as DC motors. 


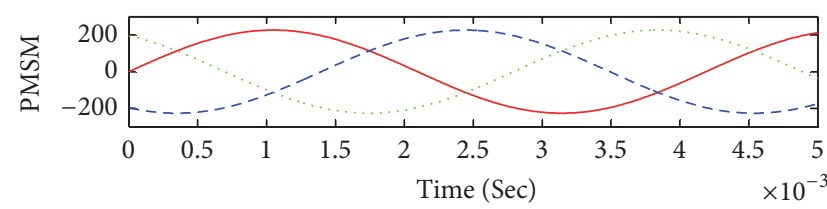

(a)

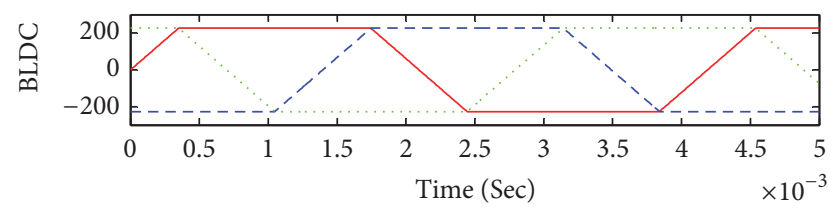

(b)

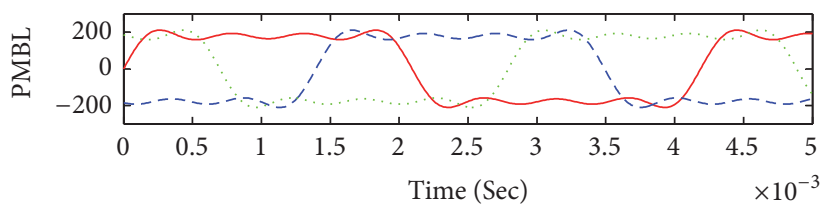

(c)

FIGURE 1: The phase back-EMF voltage waveforms induced in the stator of various types of permanent magnet brushless (PMBL) motors.

However, there are some fabricated PMBL motors whose phase back-EMF voltages are neither ideal trapezoidal like BLDCMs nor sinusoidal like PMSMs. It is due to imprecise design or restrictions during fabrication of PMBL motors. The main reasons for this issue are inappropriate distribution of the stator windings, improper form, and span of permanent magnet and saturation effects. These motors are briefly named as nonsinusoidal PMBL motor in this paper. Figure 1(c) shows a typical back-EMF voltage of nonideal PMBL motor. Employing conventional control methods of PMSMs and BLDCMs such as vector control or quasi-square current control for nonsinusoidal PMBL motors causes significant instantaneous torque ripple that depends directly on the harmonic contents of phase back-EMF voltage rather than ideal sinusoidal or trapezoidal shapes $[5,6]$. In some of special applications such as military, underwater vehicles, existence of torque ripple leads to mechanical vibration or acoustic noise that is ineligible.

On the other hand, closed-loop control of all types of PMBL motors needs electronic or electromechanical sensors for measuring of rotor speed and position. Depending on the kind of motor and also control method type, various types of position/speed sensors are used. For instance, quasisquare current control method of BLDCMs needs three cheap Hall-effect sensors, whereas in field oriented control of PMSMs optical encoders or resolvers are required that are expensive. Regarding nonsinusoidal PMBL motors, to have instantaneous constant, in most of presented methods that are reviewed afterwards, exact instantaneous value of the rotor position is essential. It means that exact position sensors must be used that are costly. In addition, the use of position/speed sensors leads to drive hardware complexity and decreases reliability of the system. Moreover, in some applications, it is not possible to install position sensors such as small motors and high-speed applications where the motor shaft is not available. Also, using of such sensors may not have economic justification in low power drives. Consequently, using of adequate position/speed estimators can reduce cost and enhances the system reliability.

This paper proposes a suitable closed-loop control of speed with minimum torque ripple for given nonsinusoidal
PMBL motors. It briefly examines previously presented control methods for PMSMs and BLDCMs and introduces the superior control method. Also in conjunction with developed control method, a novel rotor position/speed estimation based on sliding mode observer is introduced. This paper is organized as follows: in Section 2, dynamic model of nonsinusoidal PMBL motor is presented. In Section 3, various control methods for PMBL motor are briefly introduced and a superior method is presented based on selective torque harmonic elimination method. The capability of proposed control method rather than other methods is endorsed by some simulations. In Section 4 after briefly exploring the sensorless control methods of PMBL motor, various proposed sliding mode observers are described and then a new full-order sliding mode observer is suggested for nonsinusoidal PMBL motor. In Section 5, some simulations are presented in various conditions using selective torque harmonic elimination control method while the estimated rotor's position/speed is used, and finally conclusions are given in Section 6.

\section{Dynamic Model of Nonsinusoidal PMBL Motor}

The nonsinusoidal PMBL motor, unlike PMSMs, has no sinusoidal flux distribution in the air gap and using two-axis $d q$ reference frame leads to lots of errors due to existence of higher harmonics components [7]. There are two main approaches for dynamic modeling of these motors: (1) modeling in multiple $d q$ reference frames (MRF) [8]; (2) modeling in stationery three-axis $a b c$ reference frame. In the modeling based on multiple reference frames, according to harmonic contents of back-EMF voltage, multiple $d q$ reference frames are considered with speeds equal to available harmonics, and motor quantities including voltages, currents, and fluxes are transferred to these multiple $d q$ reference frames $[9,10]$. For example, if the phase back-EMF voltage contains the harmonics with order $n=1,3,5$, and 7 , then three $d q$ reference frames are considered with synchronous speed, five and seven times the synchronous speed. There is no need to 


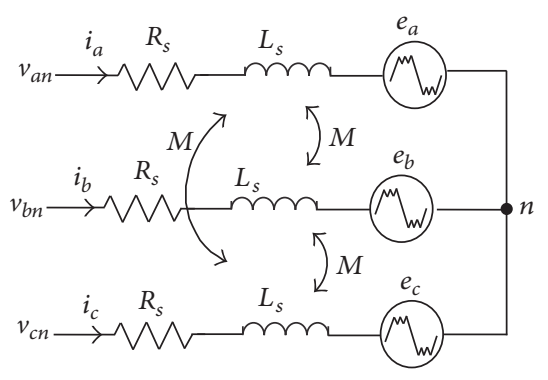

FIGURE 2: Electrical equivalent circuit of dynamic model of threephase nonsinusoidal PMBL motor in $a b c$ reference frame.

consider the third harmonic because it has no role in torque development. This type of modeling can be useful when the vector control based methods are used for the PMBL motor. This method has many computations and complex calculations and needs powerful processors. If the number of harmonics is more, complexity also increases.

Another modeling method of nonsinusoidal PMBL motor is the manner that is used for modeling of BLDC motor [11]. If the employed control method is not dependent on the model parameters, this modeling approach will be suitable. On this way, each phase of stator is modeled as series connection of stator resistance and inductance with a voltage source dependent on the actual phase back-EMF voltage waveform. Figure 2 shows the electrical equivalent circuit of dynamic model for nonsinusoidal PMBL motor. It is assumed that the stator winding is symmetrical and the core losses and the armature are negligible.

The voltage equations of three-phase nonsinusoidal PMBL motor are expressed as follows:

$$
\begin{aligned}
{\left[\begin{array}{l}
v_{a n} \\
v_{b n} \\
v_{c n}
\end{array}\right]=} & {\left[\begin{array}{ccc}
R_{s} & 0 & 0 \\
0 & R_{s} & 0 \\
0 & 0 & R_{s}
\end{array}\right] \times\left[\begin{array}{l}
i_{a} \\
i_{b} \\
i_{c}
\end{array}\right] } \\
& +\left[\begin{array}{ccc}
L_{s}-M & 0 & 0 \\
0 & L_{s}-M & 0 \\
0 & 0 & L_{s}-M
\end{array}\right] \frac{d}{d t}\left[\begin{array}{c}
i_{a} \\
i_{b} \\
i_{c}
\end{array}\right] \\
& +\left[\begin{array}{c}
e_{a} \\
e_{b} \\
e_{c}
\end{array}\right],
\end{aligned}
$$

where $v_{a n}, v_{b n}$, and $v_{c n}$ are the stator terminal voltages to natural point, $i_{a}, i_{b}, i_{c}$ are three-phase currents of the motor, $e_{a}, e_{b}, e_{c}$ are the phase back-EMF voltages, and $R_{s}, L_{s}$, and $M$ are stator resistance, self-inductance, and mutual inductance per phase. Electromagnetic torque is developed from the following:

$$
T_{e}=\frac{e_{a} i_{a}+e_{b} i_{b}+e_{c} i_{c}}{\omega_{m}}
$$

where $\omega_{m}$ is mechanical speed of rotor shaft and obeys the following rotational motion equation:

$$
T_{e}=T_{L}+J \frac{d \omega_{m}}{d t}+B_{f} \omega_{m}
$$

where $T_{L}$ is load torque and $B_{f}$ and $J$ are load friction coefficient and moment of inertia referred to rotor shaft, respectively.

\section{Control of Nonsinusoidal PMBL Motor with Minimum Torque Ripple}

There is not any unique method to control nonsinusoidal PMBL motors unlike PMSMs and BLDCMs due to different harmonic contents of the back-EMF voltage in PMBL motors. If the back-EMF voltage is similar to ideal trapezoidal one, so the control methods of BLDCMs such as quasi-square current control are mostly used. Also, if the back-EMF is similar to sinusoidal one, then control methods of the PMSMs such as vector control are used. For example, if the back-EMF voltage includes third harmonic and a very small percentage of higher multiple harmonics, the vector control provides appropriate performance, because the third harmonic is not involved in the torque development. In this section, a short review on potential methods to control nonsinusoidal PMBL motor is performed and the superior method is introduced for a typical motor.

3.1. A Review on Previous Control Methods of PMBL Motors. Due to the source of torque ripple in PMBL motors that can be caused by current commutation, tooth grooves, or nonideal waveform of back-EMF voltage, various methods have been suggested that can be grouped into five major categories [5]: reference current shaping, using estimators and observers, improvement of commutation operation, disturbance rejection of speed loop, and high-speed flow regulator saturation. The category of methods based on reference current shaping is the most common and adequate control method for torque ripple elimination. In this method, a programmed current waveform (not as sinusoidal) is injected into motor phase. The block diagram of this method is shown in Figure 3 wherein the phase reference current waveforms are created based on the rotor position, reference torque value, and available harmonic of back-EMF voltage, and then they are applied to current-controlled VSI inverter. In this method, necessary information should be known about torque ripple source.

The reference current shaping can be carried out by analyzing the components of phase back-EMF voltage in $d q$ rotating reference frames. In this way, based on the components of back-EMF voltage $\left(e_{d}\right.$ and $\left.e_{q}\right)$ the reference values of different harmonics of current are made. Afterwards, current regulation for each harmonic is carried out in corresponding $d q$ reference frame, and finally their outputs are combined together to make the output voltages. In [12], this manner has been done for a PMSM motor with nonsinusoidal back-EMF voltage with fifth harmonic order. The PI current regulators have been used for controlling the $d$ and $q$ components of 


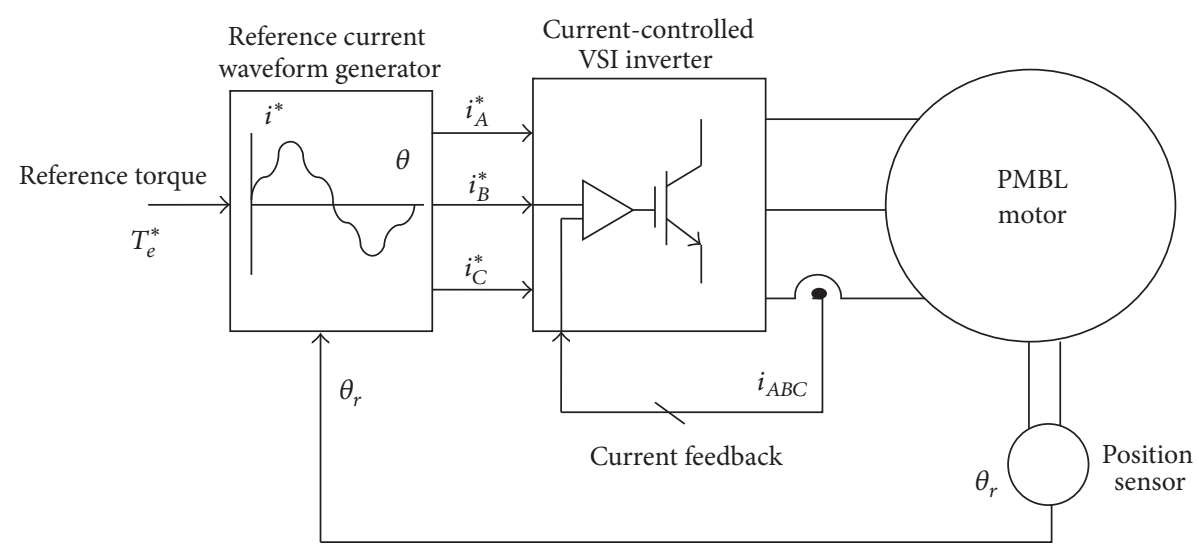

FIGURE 3: The general block diagram of nonsinusoidal PMBL motor control using reference current shaping method.

current in fundamental and fifth times speed $d q$ rotating reference frames.

The vector control of nonideal PMSMs has been improved by modifying the $q$ component of reference current in [13]. In other words, the reference component $i_{q s}$ is modified by back-EMF voltage component $e_{q}$ that changes due to higher order harmonics using air-gap power relationship in $d q$ reference frame. Also, to decrease RMS value of current, the reference current component $i_{d s}$ is put to zero. This method has less calculation than the previous method but it needs Park transformations ( $a b c$ to $d q$ ) and its inverse. A Park-like transformation has been used in [9] to reduce the torque ripple and control of a nonsinusoidal BLDC motor. Furthermore, a nonlinear state feedback linearization control law has been used in the BLDC motor model to control precisely the electromagnetic torque. Proposed control method has a lot of computations and dependency to the motor's model. Another method was proposed in [14] that used an extension of Park's transformation to model nonsinusoidal PMSM by means of the so-called pseudo- $d q$ axes reference frame. The proposed vector control algorithm is derived by decomposing the motor current into two components, one being linked to the torque and the other one to its flux. In [15], an alternative approach called "pseudovector control" (PVC) is to reduce torque ripple in BLDCM. Instead of conventional square-wave current control, it has used the principle of vector control to optimally design the waveform of reference current in such a way that the torque ripple is minimal. The advantage of proposed method rather than [12] is that the flux weakening for constant-power highspeed mode can be achieved by injecting a negative $d$-axis current into the control system, just like PMSMs. Similar attempts have been proposed in [16-18]. Two major issues of mentioned methods are high computational complexity and dependency on the motor parameters in which most of them are open loop and do not include the variations of motor parameters into control law. Furthermore, the voltage controlled-voltage source inverter (VSI) that is often used in vector and pseudovector control methods needs voltage decoupling. It increases dependency on parameters of model. In next section, selective torque harmonic elimination method is used for the nonsinusoidal PMBL motor as well as current-controlled VSI.

3.2. Selective Torque Harmonic Elimination Control of Nonsinusoidal PMBL Motor. If the harmonic contents of phase back-EMF voltage are available, it is possible to eliminate some arbitrary harmonics of torque waveform by imposing of desired reference current. This method has been applied for the BLDC motors and is called selective torque harmonic elimination or harmonic current injection $[19,20]$. It is briefly expressed for nonsinusoidal PMBL motor with phase backEMF voltage shown in Figure 1(c) that contains the harmonics of order $n=1,3,5$, and 7 with the harmonics percentage of $100 \%, 33 \%, 20 \%$, and $14 \%$, respectively. Suppose that the backEMF voltage of phase " $a$ " can be rewritten as

$$
\begin{aligned}
e_{a}(t)= & E_{1} \sin \omega t+E_{3} \sin 3 \omega t+E_{5} \sin 5 \omega t \\
& +E_{7} \sin 7 \omega t .
\end{aligned}
$$

To gain of maximum power/torque, it is desired that phase current " $a$ " is in phase with phase back-EMF voltage as

$$
i_{a}(t)=I_{1} \sin \omega t+I_{5} \sin 5 \omega t+I_{7} \sin 7 \omega t .
$$

This is because in the configuration assumed for given PMBL motor the neutral connection is not used so that current harmonics of order multiple of three cannot exist. Moreover, higher order harmonic currents than seven are not imposed because they only cause more stator copper losses. The instantaneous air-gap power of phase " $a$ " includes an average component and even higher order harmonics until 14th order as

$$
\begin{aligned}
P_{a}(t)= & e_{a} i_{a} \\
= & P_{0}+P_{2} \sin 2 \omega t+P_{4} \sin 4 \omega t+P_{6} \sin 6 \omega t+\cdots \\
& +P_{14} \sin 14 \omega t .
\end{aligned}
$$

Considering the symmetry for phase voltages and currents of different phases, the currents and voltages of two phases " $b$ " and " $c$ " have the phase shift $-120^{\circ}$ and $+120^{\circ}$ degrees relative 


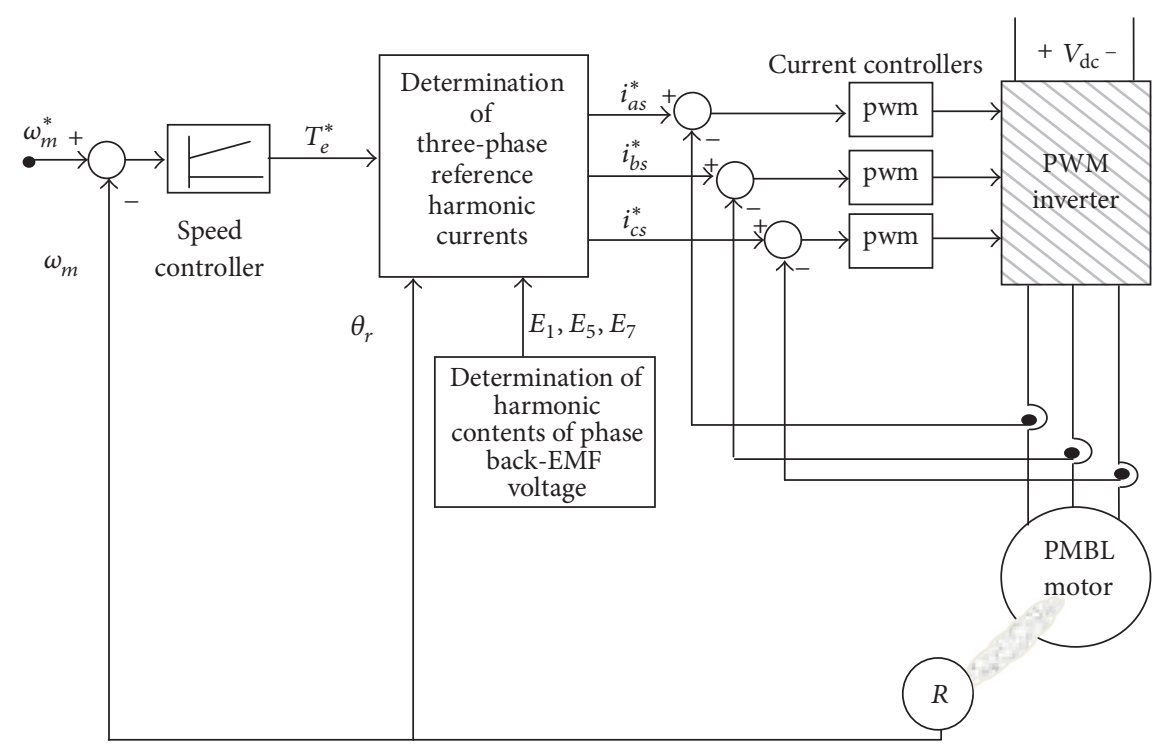

FIGURE 4: The block diagram of nonideal PMBL motor drive by selective torque harmonic method.

to phase " $a$," respectively. So, the total air-gap power will contain an average component and only harmonics of order multiple of six as

$$
P_{g}(t)=3 P_{0}+3 P_{6} \sin 6 \omega t+3 P_{12} \sin 12 \omega t
$$

and the other harmonics are eliminated. Therefore, the instantaneous torque can be written as

$$
T_{e}(t)=\frac{P_{g}}{\omega_{r}}=T_{0}+T_{6} \sin 6 \omega t+T_{12} \sin 12 \omega t,
$$

where

$$
\begin{aligned}
T_{0} & =\frac{3}{2 \omega_{r}}\left[E_{1} I_{1}+E_{5} I_{5}+E_{7} I_{7}\right], \\
T_{6} & =\frac{3}{2 \omega_{r}}\left[I_{1}\left(E_{7}-E_{5}\right)-I_{5} E_{1}+I_{7} E_{1}\right], \\
T_{12} & =\frac{3}{2 \omega_{r}}\left[-I_{5} E_{7}-I_{7} E_{5}\right] .
\end{aligned}
$$

Since the torque is proportional to the product of the backEMF and the feed current, it is possible to determine an appropriate combination of $e$ and $i$ that reduce the torque ripple to a minimum value for a given average torque $T_{0}$. Therefore, only the harmonic order multiples 5 and $7\left(I_{5}, I_{7}\right)$ are added to fundamental harmonic in which the most important torque harmonics $T_{6}$ and $T_{12}$ are cancelled out. So, for the given average torque of $T_{0}$ and $E_{1}, E_{5}$, and $E_{7}$ by solving the algebraic equation

$$
\left[\begin{array}{ccc}
E_{1} & E_{5} & E_{7} \\
E_{7}-E_{5} & -E_{1} & E_{1} \\
0 & E_{7} & E_{5}
\end{array}\right] \times\left[\begin{array}{c}
I_{1} \\
I_{5} \\
I_{7}
\end{array}\right]=\frac{2 \omega_{r}}{3}\left[\begin{array}{c}
T_{0} \\
0 \\
0
\end{array}\right]
$$

TABLE 1: Equivalent circuit parameters of employed non-sinusoidal PMBL motor.

\begin{tabular}{lcc}
\hline Quantity & Symbol & Value \\
\hline Resistance per phase & $R_{s}$ & $0.2 \Omega$ \\
Self-inductance per phase & $L_{s}$ & $0.8 \mathrm{mH}$ \\
Mutual inductance & $M$ & $0.35 \mathrm{mH}$ \\
Number of poles & $P$ & 12 \\
Constant of back-EMF voltage & $K_{e}$ & $0.15 \mathrm{~V} /(\mathrm{rad} / \mathrm{sec})$ \\
Moment of inertia & $J$ & $0.015 \mathrm{~N} \cdot \mathrm{m} / \mathrm{s}^{2}$ \\
DC link voltage & $V_{\mathrm{dc}}$ & $300 \mathrm{~V}$ \\
Rated load torque & $T_{n}$ & $15 \mathrm{~N} \cdot \mathrm{m}$ \\
\hline
\end{tabular}

the feed current harmonics are obtained from

$$
\left[\begin{array}{l}
I_{1} \\
I_{5} \\
I_{7}
\end{array}\right]=\left[\begin{array}{c}
1.0063 \\
-0.047 \\
0.0235
\end{array}\right] \frac{2 \omega_{r}}{3} T_{0}
$$

By imposing three-phase reference currents with the first, fifth, and seventh harmonics amplitudes as obtained, the torque ripple due to harmonics of phase back-EMF voltage will be exactly cancelled.

Figure 4 shows the block diagram of speed closed-loop system of nonsinusoidal PMBL motor controlled by using selective torque harmonics elimination method. The used motor has rated power and speed of $2.5 \mathrm{~kW}$ and $1500 \mathrm{rpm}$ whose equivalent circuit parameters are listed in Table 1.

Figure 5 shows the simulation results of motor behavior by this method. The reference speed reaches its rated value within tenth of a second and the motor actual speed tracks it as well. The reference current, which is determined by the control system, is not sinusoidal and includes harmonics with order multiples five and seven. Three hysteresis current controllers are employed for tracking of reference currents 

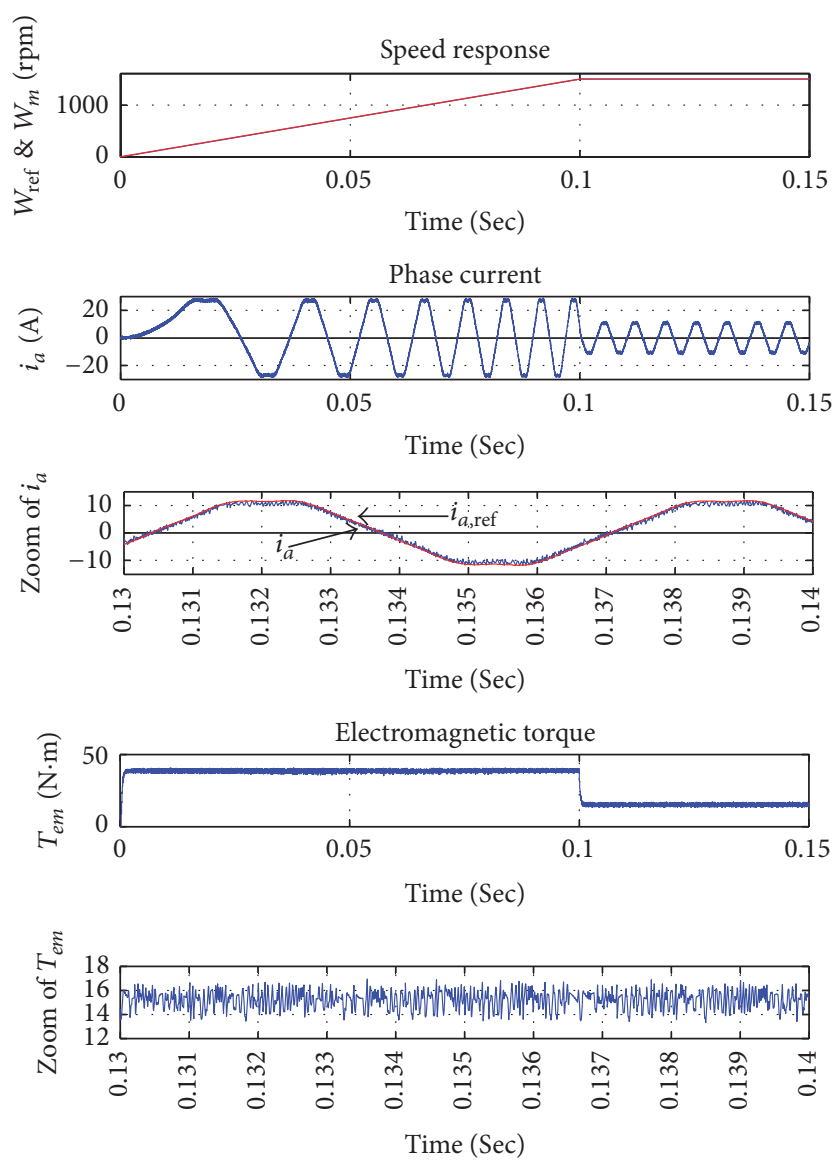

FIGURE 5: Simulation results of the nonsinusoidal PMBL motor control by the selective torque harmonic elimination method.

and the results show the current response is satisfactory. The electromagnetic torque reaches its determined maximum value of $40 \mathrm{~N} \cdot \mathrm{m}$ during the startup and at final speed it settles to the load torque $\mathrm{N} \cdot \mathrm{m}$. The torque ripple peak-to-peak value is $2.7 \mathrm{~N} \cdot \mathrm{m}$ or $16 \%$ at final speed which shows a significant improvement rather than other suggested methods.

To prove this claim, the motor behavior is also simulated by using three common control methods of PMBL motors including three-phase quasi-square current control, direct torque control, and vector control. The simulation results of these methods are shown in Figure 6. The torque ripple value of these methods is compared with selective torque harmonic elimination method as summarized in Table 2. Simulation results confirm that proposed selective torque harmonic elimination method has significant advantages such as the ease of implementation, low calculations, and less torque ripple value compared to other methods.

\section{Sensorless Control of Nonsinusoidal PMBL Motor}

For nonsinusoidal PMBL motor control presented in previous section, the precise rotor position information is essential for generating of references currents. The rotor position is measured by accurate electromechanical sensors such as
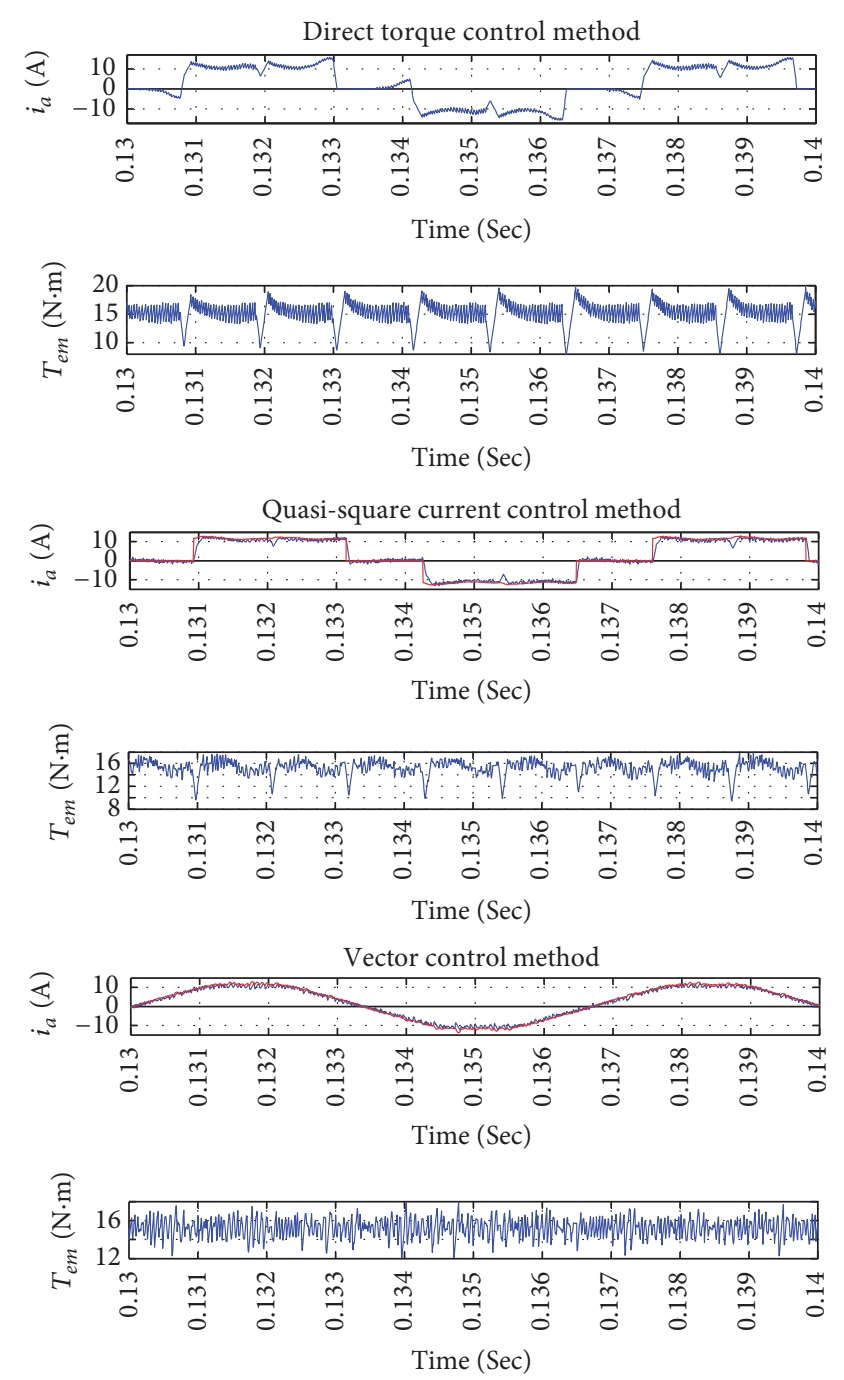

FIGURE 6: Simulation results for current and torque waveforms of nonsinusoidal PMBL motor control by using other conventional methods (direct torque control, quasi-square current control, and vector control).

TABLE 2: Comparison of the relative torque ripple of non-sinusoidal PMBL motor by using various control methods in the final speed.

\begin{tabular}{lc}
\hline Control method & THD of torque \\
\hline $\begin{array}{l}\text { Direct torque control } \\
\text { Quasi-square current control with } \\
\text { three-phase current feeding }\end{array}$ & $80 \%$ \\
$\begin{array}{l}\text { Vector control } \\
\text { Selective torque harmonic elimination } \\
\text { control }\end{array}$ & $45 \%$ \\
\hline
\end{tabular}

encoders or resolvers. But using the estimator of the rotor position and speed in the permanent magnet motor drives control is also highly regarded to reduce the cost of design and construction and also enhance reliability [22]. Various methods have been proposed to estimate the position and speed of PMBL motors [21, 23]. As follows, a brief overview 


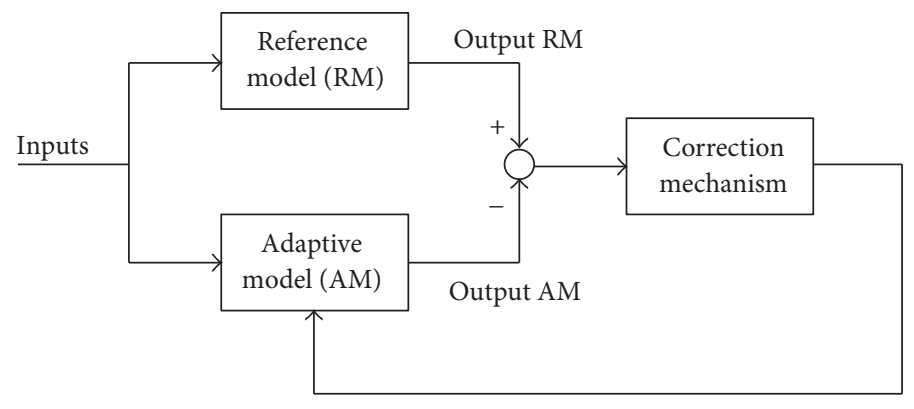

FIGURE 7: Block diagram of closed-loop observers [21].

on the types of sensorless methods is explored, and then some attempts to design of sliding mode observers are investigated and finally a new sliding mode observer is investigated for nonsinusoidal PMBL motor.

\subsection{Review on Sensorless Control Methods of PMBL Motors.} The position estimation methods of PMBL motors can be divided into two categories: open-loop and closed-loop methods [24]. The open-loop methods obtain the rotor position information from the motor model and direct measurement of voltage terminals without using any internal correction mechanism. These classes of methods are used due to their simplicity and have various types including methods based on the back-EMF voltage, methods based on stator flux linkage, methods based on inductance changes, and methods based on high frequency signal injection. Despite the simplicity of open-loop methods, they are faced with many restrictions including poor dynamic response, sensitivity to parameters of motor, and difficulty at low speeds, especially at startup.

In contrast with the open-loop methods, the closed-loop techniques are based on observer schemes that use an internal correction mechanism. These methods are mainly based on model reference adaptive systems (MRAS) including Luenberger observer, disturbance and sliding mode observer, and Kalman filter. Figure 7 shows the generic block diagram of closed-loop observers composing the reference model and the adaptive model. The reference model is the motor whose outputs are the currents, while the adaptive model is the motor model that estimates the motor currents. The error between the estimated currents and the measured ones is fed back to the adaptive model. A simplified classification of the closed-loop methods is the reduced-order observers and full-order observers. The reduced-order observers are closed-loop schemes that do not contain the mechanical motor model and so have fewer dynamic equations and computations. They are based on two approaches: current observer and flux observer. The output of reduced-order observers is mainly stator currents or fluxes, and to determine rotor position/speed extra computation is needed.

With respect to reduced-order observers, the full-order observers include the mechanical model whose output is the rotor position that is used to get the estimated currents via the inverse magnetic model. The error between the estimated currents and the measured ones is fed back to the adaptive model. The closed-loop observers are more accurate and have less error but are often based on the motor dynamic modeling and are dependent on equivalent circuit parameters. So the used algorithm must be designed as robust and adaptive.

Among closed-loop observers, the sliding mode observers (SMO) have satisfactory dynamic response and good robustness to the dynamic model parameters changes and linear and nonlinear unmodeled dynamics. Major presented sliding mode observers estimate the phase back-EMF voltage components in the stationary $\left(e_{\alpha}, e_{\beta}\right)$ or rotating $\left(e_{d}, e_{q}\right)$ two-axis reference frames using measured stator currents and voltages. Then, the rotor's position and speed are calculated from mathematical relations. For instance, in [25], for a given BLDC motor, the voltages values of $e_{\alpha}$ and $e_{\beta}$ have been estimated using a second-order SMO, and the rotor position is obtained from

$$
\theta_{r}=\frac{\pi}{2}-\tan ^{-1}\left(\frac{e_{\beta}}{e_{\alpha}}\right)
$$

and to calculate of the rotor's speed, and to calculate the speed of rotor, the derivative of position of rotor has to be determined. Derivation may lead to significant computational error due to switching noises. Similar attempts have been presented in $[26,27]$ where back-EMF components $e_{d}$ and $e_{q}$ in rotating $d q$ reference frame have been estimated by the same way. To avoid errors and problems due to derivation, some researches have been suggested using of phase-locked loop (PLL) to calculate motor speed from estimated position that actually increases the order of dynamic equations of the observer [24, 28].

4.2. Design of Full-Order Sliding Mode Observer for Nonsinusoidal PMBL Motor. As mentioned in previous section, due to advantages of sliding mode observers and computational errors in reduced-order observers, a novel full-order sliding mode observer is presented to estimate the rotor's position and speed of nonsinusoidal PMBL motor as follows. The designed observer is especially for nonlinear uncertain systems. The observer inputs are stator voltage components in $\alpha \beta$ stationary reference frame $\left(v_{s \alpha}, v_{s \beta}\right)$. The system state variables are electrical angular position and speed of rotor and two stator current components in $\alpha \beta$ stationary reference frame as follows:

$$
x^{T}=\left[\theta_{r}, \omega_{r}, i_{s \alpha}, i_{s \beta}\right] .
$$


The dynamic equations of PMBL motor expressed by (1) can be rewritten in $\alpha \beta$ reference frame as

$$
\begin{aligned}
\frac{d \theta_{r}}{d t} & =\omega_{r}, \\
\frac{d \omega_{m}}{d t} & =\frac{1}{J}\left(\frac{3}{2}\left(\frac{e_{\alpha} i_{\alpha}+e_{\beta} i_{\beta}}{\omega_{m}}\right)-T_{L}-B \omega_{m}\right), \\
\frac{d i_{s \alpha}}{d t} & =-\frac{R_{s}}{L_{s}} i_{s \alpha}+\frac{1}{L_{s}} v_{s \alpha}-\frac{1}{L_{s}} e_{\alpha}, \\
\frac{d i_{s \beta}}{d t} & =-\frac{R_{s}}{L_{s}} i_{s \beta}+\frac{1}{L_{s}} v_{s \beta}-\frac{1}{L_{s}} e_{\beta},
\end{aligned}
$$

where $e_{\alpha}$ and $e_{\beta}$ are components of phase back-EMF voltage that are obtained from Clark transformation of nonsinusoidal waveform in Figure 1(c). Also the mechanical speed $\omega_{m}$ should be replaced with equivalent electrical speed $\omega_{r}$ in (15). The above state space equations can be expressed in the general form as follows:

$$
\begin{aligned}
& \dot{x}=A x+B u+\Phi(x, u)+D f(y, u), \\
& y=C x,
\end{aligned}
$$

where $x, u$, and $y$ vectors are the state variables, inputs, and outputs, respectively. $\Phi(x, u)$ is the known nonlinear term of the system and is assumed to be Lipschitz with respect to $x$ for all $u$ [29]. The function $f(y, u)$ represents the unknown term of the systems that is bounded by the known function $\rho(y, u)$. The input vector $u$ includes the stator voltage components of $v_{s \alpha}$ and $v_{s \beta}$; the output vector $y$ includes $i_{s \alpha}$ and $i_{s \beta}$ stator current components. The matrices $A, B, C$, and $D$ and functions $\Phi(x, u)$ and $f(y, u)$ in (18) are defined in Appendix A. Moreover, the following conditions must be met for this observer:

(1) $\operatorname{rank}(C D)=\operatorname{rank}(D)$.

(2) All the invariant zeros of the matrix triple $A, D, C$ lie in the left half plane.

For this system, the condition of $\operatorname{rank}(C D)=\operatorname{rank}(D)=$ 2 is satisfied. Also, the system has not any zero; therefore condition 2 is satisfied.

Then, the state space equations of system (18) can be written as follows:

$$
\begin{aligned}
\dot{x}_{1} & =A_{11} x_{1}+A_{12} x_{2}+B_{1} u+\Phi_{1}(x, u), \\
\dot{x}_{2} & =A_{21} x_{1}+A_{22} x_{2}+B_{2} u+\Phi_{2}(x, u)+D_{2} f(y, u), \\
y & =C_{2} x_{2},
\end{aligned}
$$

where $\Phi_{1}$ and $\Phi_{2}$ are the first two components and the last two components of matrix $\Phi(x, u)$, respectively, and $B_{1}$ and $B_{2}$ are the first two rows and the last two rows of matrix $B$, respectively. Given that $f(y, u)$ are the output uncertainties, then the first two rows which are related to $\dot{x}_{1}$ are zero and $D_{2}$ is the last two rows of matrix $D$.
Now, let us to introduce a coordinate transformation $z=T x$ for designing the sliding mode observer, where $T$ is defined as follows:

$$
\begin{aligned}
T & =\left[\begin{array}{ll}
I_{2} & L \\
0 & I_{2}
\end{array}\right], \\
T^{-1} & =\left[\begin{array}{cc}
I_{2} & -L \\
0 & I_{2}
\end{array}\right] .
\end{aligned}
$$

Then, the state equations are obtained in the new coordinate system as follows:

$$
\begin{aligned}
\dot{z}_{1}= & \left(A_{11}+L A_{21}\right) z_{1} \\
& +\left(A_{12}-A_{11} L+L\left(A_{22}-A_{21} L\right)\right) z_{2} \\
& +\left[\begin{array}{ll}
I_{2} & L
\end{array}\right] B u+\left[\begin{array}{ll}
I_{2} & L
\end{array}\right] \Phi\left(T^{-1} z, u\right), \\
\dot{z}_{2}= & A_{21} z_{1}+\left(A_{22}-A_{21} L\right) z_{2}+B_{2} u+\Phi_{2}\left(T^{-1} z, u\right) \\
& +D_{2} f(y, u), \\
y= & C_{2} z_{2} .
\end{aligned}
$$

Then in the new $z$ coordinates, sliding mode observer equations have the following form:

$$
\begin{aligned}
\dot{\vec{z}}_{1}= & \left(A_{11}+L A_{21}\right) \widehat{z}_{1} \\
& +\left(A_{12}-A_{11} L+L\left(A_{22}-A_{21} L\right)\right) \widehat{z}_{2} \\
& +\left[\begin{array}{ll}
I_{2} & L
\end{array}\right] B u+\left[\begin{array}{ll}
I_{2} & L
\end{array}\right] \Phi\left(T^{-1} \widehat{z}, u\right), \\
\dot{\vec{z}}_{2}= & A_{21} \widehat{z}_{1}+\left(A_{22}-A_{21} L\right) \widehat{z}_{2}+B_{2} u+\Phi_{2}\left(T^{-1} \widehat{z}, u\right) \\
& +D_{2} f(y, u), \\
y= & C_{2} \widehat{z}_{2},
\end{aligned}
$$

where

$$
v=\rho \cdot \operatorname{sign}\left(y-C_{2} \bar{z}_{2}\right)
$$

and $\rho$ is positive scalar. Dynamic equations of the estimation error vector are obtained by combining (21) with (22)-(23) as follows:

$$
\begin{aligned}
\dot{e}_{1}= & \left(A_{11}+L A_{21}\right) e_{1} \\
& +\left[I_{2} L\right]\left(\Phi\left(T^{-1} z, u\right)-\Phi\left(T^{-1} \widehat{z}, u\right)\right) \\
\dot{e}_{y}= & C_{2} A_{21} e_{1}+\left(C_{2}\left(A_{22}-A_{21} L\right) C_{2}^{-1}+C_{2} K\right) e_{y} \\
& +C_{2} D_{2} f(y, u)-C_{2} v \\
& +C_{2}\left(\Phi_{2}\left(T^{-1} z, u\right)-\Phi_{2}\left(T^{-1} \widehat{z}, u\right)\right) .
\end{aligned}
$$

According to (24), the matrix $L$ should be chosen so that the term $\left(A_{11}+L A_{21}\right)$ is stable. Also, the gain matrix $K$ can be considered as follows:

$$
K=-\left(A_{22}-A_{21} L\right) C_{2}^{-1}+C_{2}^{-1} A_{s},
$$




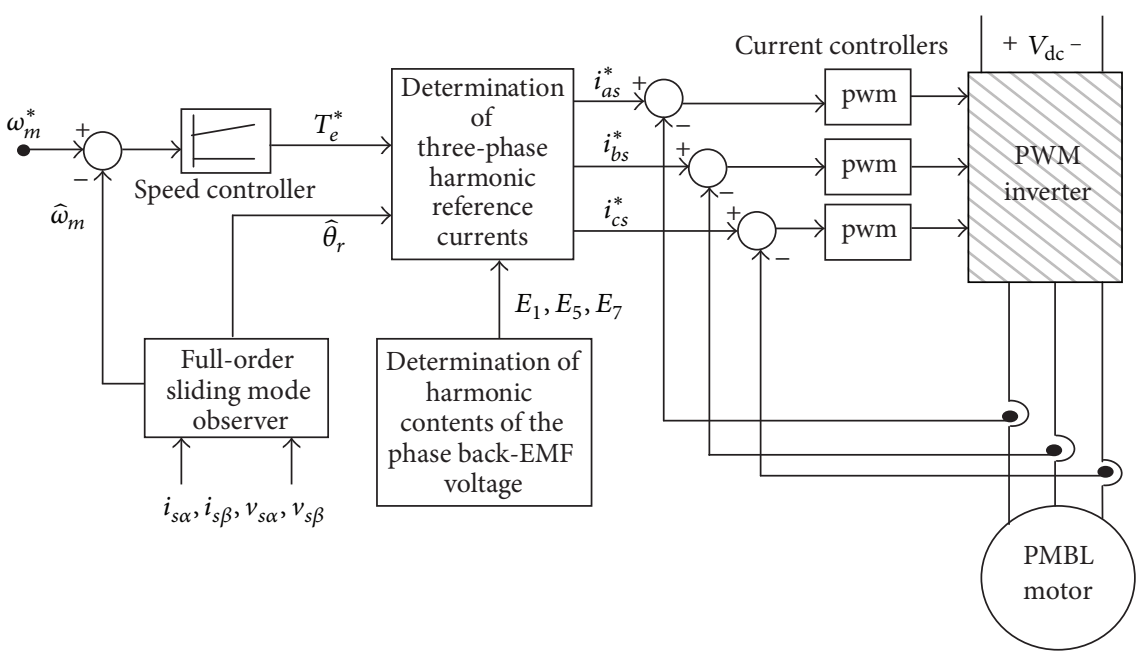

FIGURE 8: Block diagram of SMO sensorless control system by selective torque harmonic elimination method for nonsinusoidal PMBL motor.

where $A_{s}$ is a symmetric positive definite matrix to ensure that the following matrix is symmetric negative definite:

$$
C_{2}\left(A_{22}-A_{21} L\right) C_{2}^{-1}+C_{2} K
$$

As a result, the linearized nominal system matrix of the estimation error dynamic system is stable and the estimation error asymptotically tends to zero. The linearized system matrix is described by

$$
\left[\begin{array}{cc}
A_{11}+L A_{21} & 0 \\
C_{2} A_{21} & C_{2}\left(A_{22}-A_{21} L\right) C_{2}^{-1}+C_{2} K
\end{array}\right] .
$$

For this system, the sliding surface is considered as

$$
S=\left\{\left(e_{1}, e_{y}\right) \mid e_{y}=0\right\}
$$

In this case, according to the mentioned conditions for selection of matrices $L$ and $K$, the best response is obtained for $L=-e p s I_{2}$ and $A_{s}=2000 I_{2}$ due to the given uncertainty $f(y, u)$; the value of $\rho$ is chosen to 20 . The state estimation error dynamic equations represent the sliding dynamics when it is limited to the sliding surface $S$. It is only necessary to ensure stability of $e_{1}$ so that asymptotic stability of these equations is proved relative to the sliding surface. For this purpose, Lyapunov function can be considered as $V=e_{1}^{T} P e_{1}$. The stability proof of this $V$ function is briefly presented in Appendix B.

\section{Simulation of Sensorless Control System of Nonsinusoidal PMBL Motor}

In this section, the closed-loop control system of the nonsinusoidal PMBL motor with selective torque harmonic elimination method is simulated by using estimated position and speed of the rotor of introduced sliding mode observer. The block diagram of the system is shown in Figure 8 .
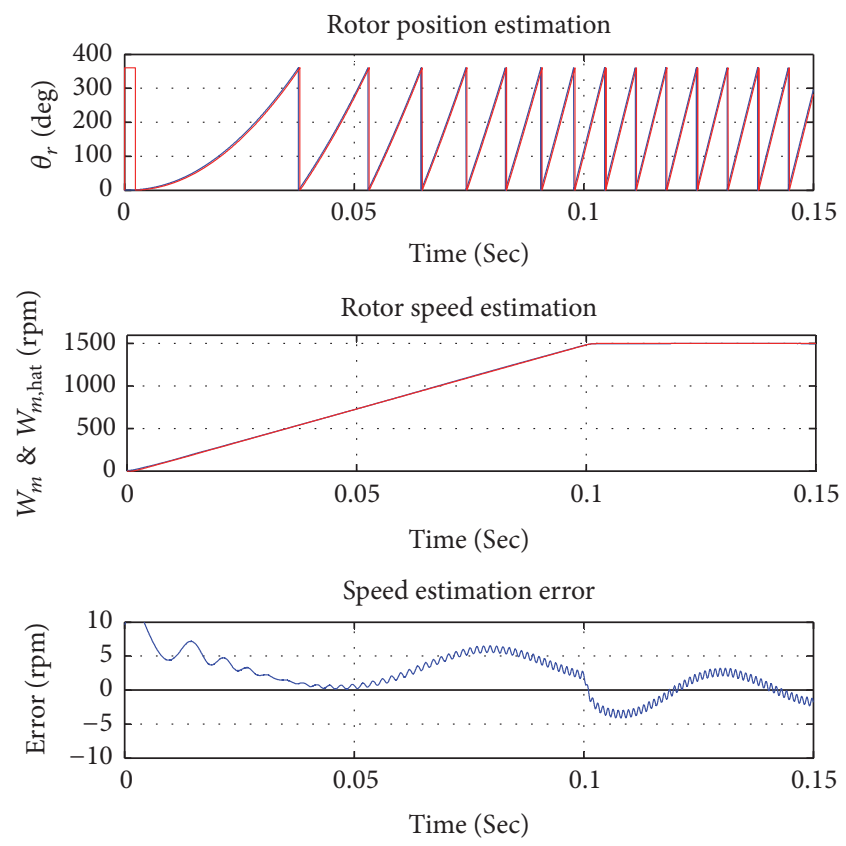

FIGURE 9: Estimated position and speed of nonsinusoidal PMBL motor in the sensorless closed-loop control system.

The estimated position and speed of the rotor are compared to the real position and speed in Figure 9. The maximum amount of position error is 10 degrees where its main reason is the use of low filtered voltages and currents values of the stator as observer inputs. However, this amount of error does not affect the speed tracking. Also, the speed tracking error is less than $8 \mathrm{rpm}$ or $\% 0.6$ of reference speed. Figure 10 shows developed electromagnetic torque where the torque ripple is about $4.5 \mathrm{~N} \cdot \mathrm{m}$ at final speed. The increase of torque ripple compared to case with sensor shown in Figure 5 is due to the estimated position error. It is easy to show that the torque ripple has been mentioned far more than 

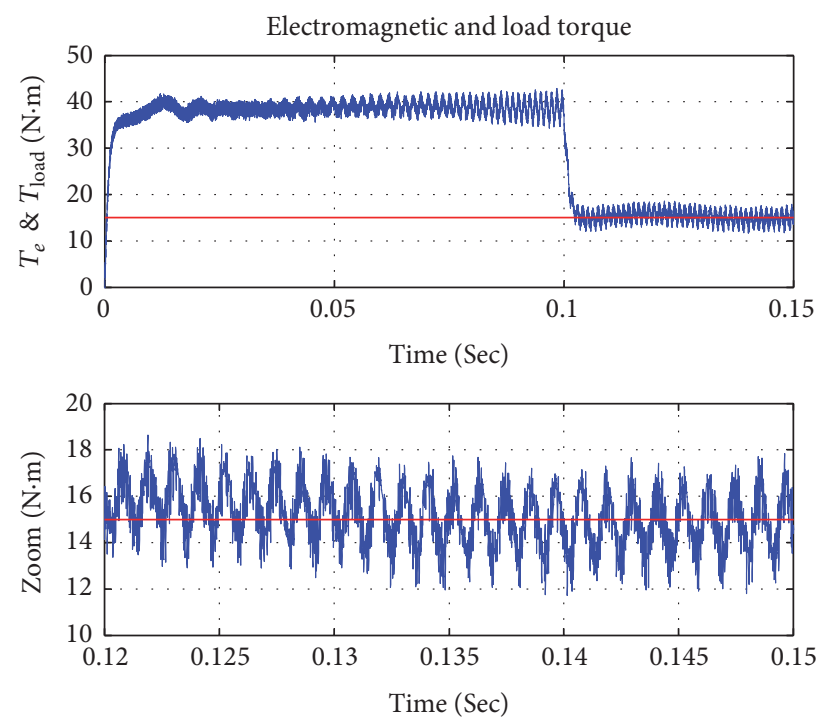

FIGURE 10: Developed electromagnetic torque in the sensorless closed-loop control system of nonsinusoidal PMBL motor.
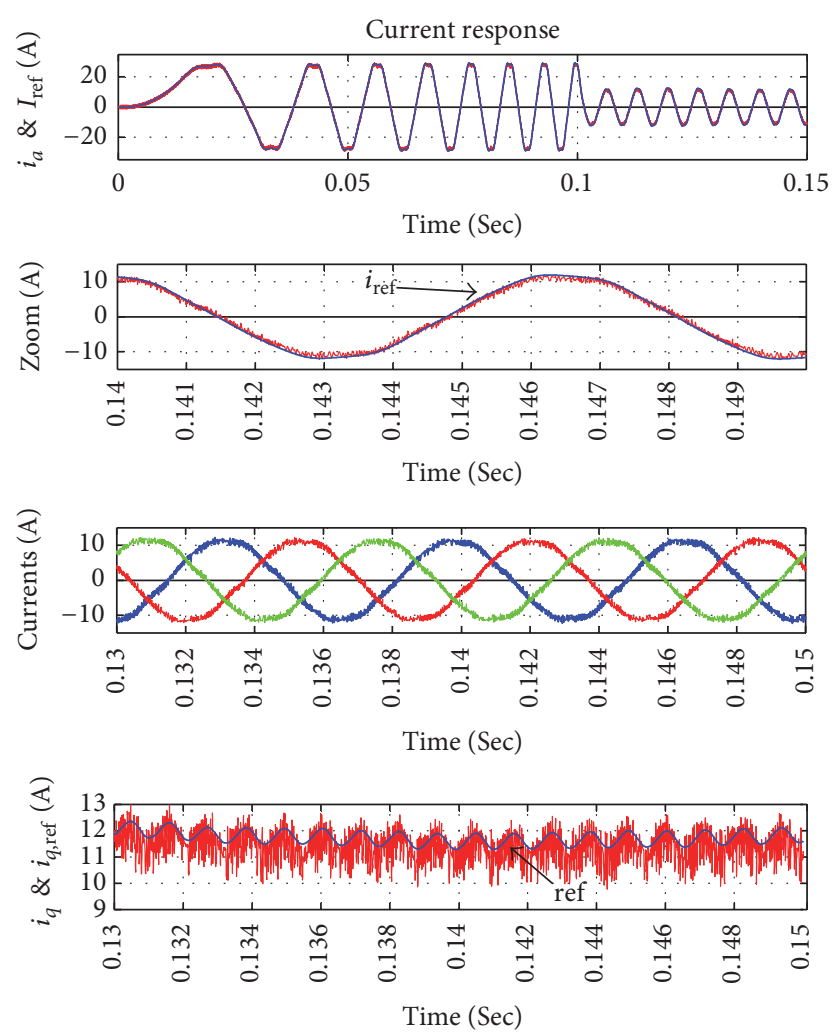

FIGURE 11: Nonsinusoidal PMBL motor currents waveforms in the sensorless closed-loop control system.

$4.5 \mathrm{~N} \cdot \mathrm{m}$ in the event that other control methods are used by the estimated position and speed via SMO.

Figure 11 shows current response of the driving system. Tracking of phase current has been performed well. Also, the reference waveform of stator current component $q$ and
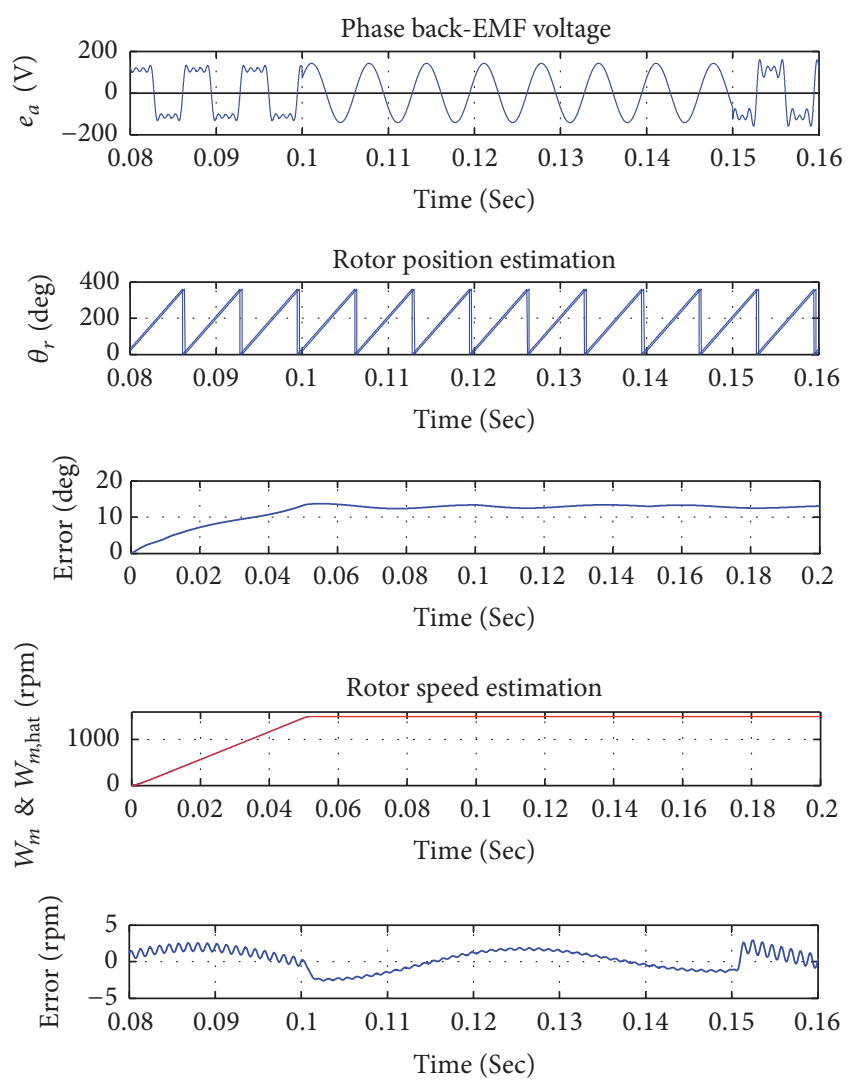

FIGURE 12: Estimated rotor position and speed of nonsinusoidal PMBL motor during the change of harmonic contents of phase backEMF voltage.

its real value have been shown. Since the reference current $i_{q s}$ contains the fifth and seventh harmonics it has periodical variations. The real value of $i_{q s}$ has high frequency oscillation due to hysteresis current controller and chattering of SMO.

To verify the robustness of sliding mode observer to variations of motor parameters, the harmonic contents of phase back-EMF voltage are changed during motor operation. The phase back-EMF voltage at the time $t=0.1 \mathrm{sec}$ changes to quite sinusoidal form and then at the time $t=0.15 \mathrm{sec}$ changes to waveform with harmonics of orders $1,3,5$, and 7 with amplitudes of $100 \%, 33 \%, 20 \%$, and $13 \%$ of fundamental harmonic. It should be noted that this scenario may not happen for a real motor and we want to show the capability of sliding mode observer against uncertain model of the system. The changes of the phase back-EMF voltage and tracking error of the rotor position and speed are shown in Figure 12. The tracking error has not significantly changed while the back-EMF voltage changes which means that the SMO is robust to uncertainties. Figure 13 shows the motor torque and current waveforms during this scenario. The torque ripple decreases while the back-EMF waveform changes to be sinusoidal. 

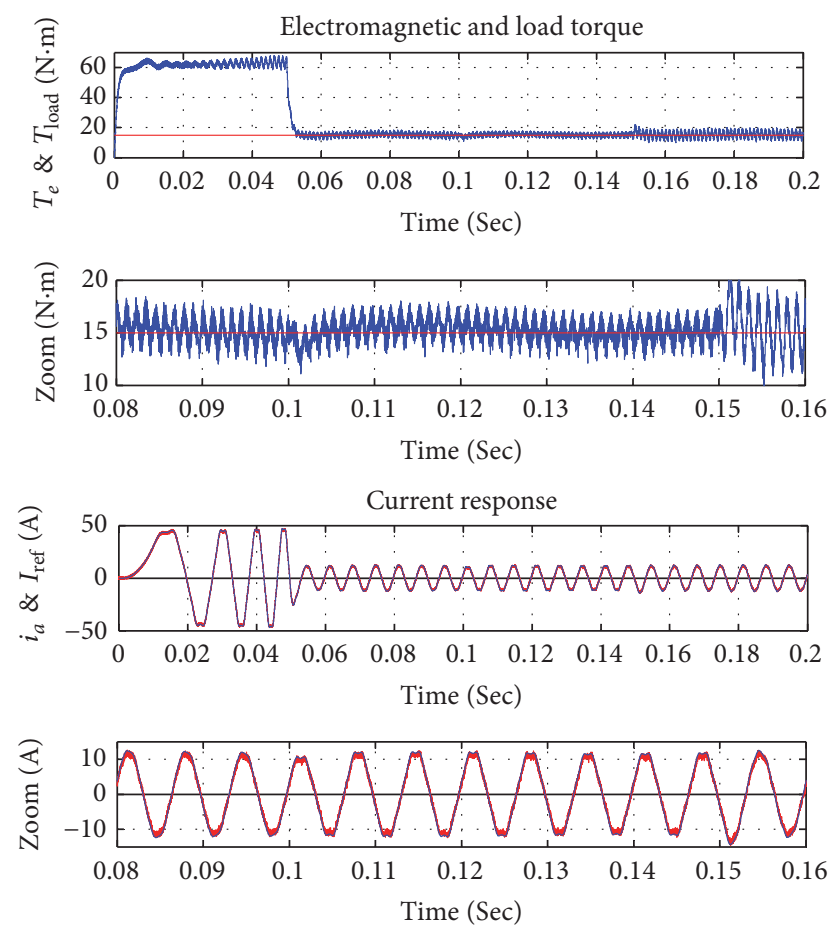

Figure 13: The motor current and torque waveforms during the change of harmonic contents of phase back-EMF voltage.

\section{Conclusion}

A novel sensorless control based on full-order sliding mode observer for closed-loop speed control of a nonsinusoidal PMBL motor has been developed in this paper. It is accompanied with torque ripple minimization strategy using selective harmonic elimination method. Proposed control method does not have any dependency on the motor parameters except harmonic contents of phase back-EMF voltage and it uses current-controlled VSI. Also, contrary to vector controlled based method, it does not need any Park transformations and voltage decoupling. Torque ripple resulting from proposed method is at least among various proposed techniques. To reduce the cost and to enhance the reliability, a four-order new sliding mode observer (SMO) has been developed to estimate the instant position and speed of PMBL motor directly. Developed SMO has special features including fast response, less estimation error, and robustness against uncertainties of the motor parameters such as back-EMF or stator resistance. Moreover, it can run the motor as closedloop scheme from the standstill without employing openloop starting that is relevant in other open-loop and some closed-loop estimators.

The simulation results endorse satisfactory behavior of torque ripple reduction control as well as speed estimator. To enhance the performance of the proposed drive, it is possible to predict the harmonic contents of phase back-EMF voltage via suitable observers or via more calculations with proposed sliding mode observer.

\section{Appendix}

\section{A. Matrices and Functions Presented in (18)}

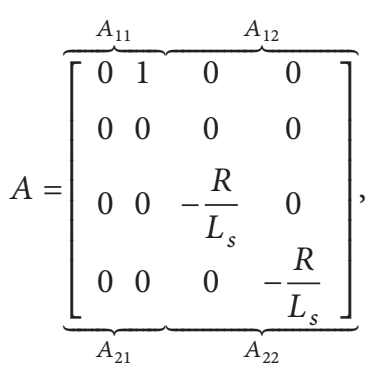

$B=\overbrace{B_{2}}^{\left[\begin{array}{cc}0 & 0 \\ 0 & 0 \\ \frac{1}{L_{s}} & 0 \\ 0 & \frac{1}{L_{s}}\end{array}\right]}$,

$C=\overbrace{\left[\begin{array}{llll}0 & 0 & 1 & 0 \\ 0 & 0 & 0 & 1\end{array}\right]}^{C_{1}} C_{2}$,

$D f(y, u)=\underbrace{\left[\begin{array}{cc}0 & 0 \\ 0 & 0 \\ -0.1 \frac{R_{s}}{L_{s}} & 0 \\ 0 & -0.1 \frac{R_{s}}{L_{s}}\end{array}\right]}_{D_{2}}$,

(A.1)

$$
\begin{aligned}
& \Phi(x, u)=\left[\frac { 1 } { J } \frac { 3 } { 2 } K _ { e } ( \frac { P } { 2 } ) ^ { 2 } \left(i _ { s \alpha } \left(\sin \theta_{r}+0.25 \sin 3 \theta_{r}\right.\right.\right. \\
& \left.+0.1 \sin 5 \theta_{r}+0.02 \sin 7 \theta_{r}\right)-i_{s \beta}\left(\cos \theta_{r}\right. \\
& \left.+0.25 \cos 3 \theta_{r}+0.1 \cos 5 \theta_{r}+0.02 \cos 7 \theta_{r}\right)-\frac{2}{P} \\
& \left.\cdot T_{L}-B_{m} \frac{2}{P} \omega_{r}\right)-\frac{K_{e}}{L_{s}} \omega_{r}\left(\sin \theta_{r}+0.25 \sin 3 \theta_{r}\right. \\
& \left.+0.1 \sin 5 \theta_{r}+0.02 \sin 7 \theta_{r}\right) \frac{K_{e}}{L_{s}} \omega_{r}\left(\cos \theta_{r}+0.25\right. \\
& \left.\left.\cdot \cos 3 \theta_{r}+0.1 \cos 5 \theta_{r}+0.02 \cos 7 \theta_{r}\right)\right] .
\end{aligned}
$$




\section{B. Stability Proof of Lyapunov Function $V=e_{1}^{T} P e_{1}$}

From what is given function is derived as follows:

$$
\begin{aligned}
\dot{V}= & e_{1}^{T}\left(\left(A_{11}+L A_{21}\right)^{T} P+P\left(A_{11}+L A_{21}\right)\right) e_{1} \\
& +2 e_{1}^{T} P\left[I_{2} L\right]\left(\Phi\left(T^{-1} z, u\right)-\Phi\left(T^{-1} \widehat{z}, u\right)\right) \\
= & e_{1}^{T}\left(\bar{A}^{T} \bar{P}^{T}+\bar{P} \bar{A}\right) e_{1} \\
& +2\left(\bar{P}^{T} e_{1}\right)\left(\Phi\left(T^{-1} z, u\right)-\Phi\left(T^{-1} \widehat{z}, u\right)\right),
\end{aligned}
$$

where

$$
\begin{gathered}
\bar{P}:=P\left[\begin{array}{ll}
I_{2} & L
\end{array}\right], \\
\bar{A}:=\left[\begin{array}{l}
A_{11} \\
A_{21}
\end{array}\right] .
\end{gathered}
$$

According to famous Young's inequality $\left(2 X^{T} Y \leq \varepsilon X^{T} X+\right.$ $\left.(1 / \varepsilon) Y^{T} Y\right)$, which exists for each scalar $\varepsilon>0$, inequality, the relation $\dot{V}$ is obtained as follows [29]:

$$
\begin{aligned}
\dot{V} \leq & e_{1}^{T}\left(\bar{A}^{T} \bar{P}^{T}+\bar{P} \bar{A}\right) e_{1}+\varepsilon e_{1}^{T} \overline{P P}^{T} e_{1} \\
+ & \frac{1}{\varepsilon}\left(\Phi\left(T^{-1} z, u\right)-\Phi\left(T^{-1} \widehat{z}, u\right)\right)^{T} \\
& \cdot\left(\Phi\left(T^{-1} z, u\right)-\Phi\left(T^{-1} \widehat{z}, u\right)\right) .
\end{aligned}
$$

As a result,

$$
\begin{aligned}
\dot{V} \leq & e_{1}^{T}\left(\bar{A}^{T} \bar{P}^{T}+\bar{P} \bar{A}\right) e_{1}+\varepsilon e_{1}^{T} \overline{P P}^{T} e_{1} \\
& +\frac{1}{\varepsilon}\left(L_{\Phi}\right)^{2}\left\|e_{1}\right\|^{2} \\
= & e_{1}^{T}\left(\bar{A}^{T} \bar{P}^{T}+\bar{P} \bar{A}+\varepsilon \overline{P P}^{T}+\frac{1}{\varepsilon}\left(L_{\Phi}\right)^{2} I\right) e_{1} .
\end{aligned}
$$

So, if the following relationship is established,

$$
\bar{A}^{T} \bar{P}^{T}+\bar{P} \bar{A}+\varepsilon \overline{P P}^{T}+\frac{1}{\varepsilon}\left(L_{\Phi}\right)^{2} I<-\alpha P,
$$

in this case, we have

$$
\dot{V} \leq-\alpha e_{1}^{T} P e_{1}=-\alpha V .
$$

In other words, the designed sliding mode observer always remains stable.

\section{Competing Interests}

The authors declare that they have no competing interests.

\section{References}

[1] R. Krishnan, Permanent-Magnet Synchronous and Brushless DC Motor Drives, John Wiley \& Sons, 2002.
[2] J. F. Gieras and M. Wing, Permanent Magnet Motor Technology: Design and Applications, Marcel Dekker, Inc, New York, NY, USA, 2nd edition, 2002.

[3] D. C. Hanselman, Brushless Permanent-Magnet Motor Design, Magna Physics, Lebanon, Ohio, USA, 2006.

[4] E. Klintberg, Comparison of control approaches for permanent magnet motors (Master of Science) [M.S. thesis], Department of Energy and Environment, Chalmers University of Technology, Göteborg, Sweden, 2013.

[5] T. M. Jahns and W. L. Soong, "Pulsating torque minimization techniques for permanent magnet AC motor drives-a review," IEEE Transactions on Industrial Electronics, vol. 43, no. 2, pp. 321-330, 1996.

[6] A. N'diaye, C. Espanet, and A. Miraoui, "Reduction of the torque ripples in brushless PM motors by optimization of the supplytheoretical method and experimental implementation," in Proceedings of the 2004 IEEE International Symposium on Industrial Electronics (IEEE-ISlE '04), pp. 1345-1350, Ajaccio, France, May 2004.

[7] A. Halvaei Niasar, H. Moghbelli, and A. Vahedi, "Modeling and simulation methods for brushless DC motor drives," in Proceedings of the 1st International Conference on Modeling, Simulation and Applied Optimization (ICMSAO '05), vol. 5, pp. 24-167, Sharjah, United Arab Emirates, 2005.

[8] P. L. Chapman, S. D. Sudhoff, and C. A. Whitcomb, "Multiple reference frame analysis of non-sinusoidal brushless DC drives," IEEE Transactions on Energy Conversion, vol. 14, no. 3, pp. 440-446, 1999.

[9] D. Grenier and L. A. Dessaint, "A park-like transformation for the study and the control of a non-sinusoidal brushless DC motor," in Proceedings of the 21st International Conference on Industrial Electronics, Control and Instrumentation (IEEE IECON' '95, pp. 837-843, 1995.

[10] H. Lei and H. A. Toliyat, "BLDC motor full speed range operation including the flux-weakening region," in Proceedings of the IEEE Annual Industry Applications Conference (IAS '03), vol. 1, pp. 618-624, Salt Lake City, Utah, USA, 2003.

[11] B. K. Lee, B. Fahimi, and M. Ehsani, "Dynamic modeling of brushless DC motor drives," in Proceedings of the European Conference on Power Electronics and Applications (EPE '01), Graz, Austria, 2001.

[12] F. Bonvin and Y. Perriard, "BLDC motor control in multiple dq axes", in Proceedings of the 8th International Conference on IEE Power Electronics and Variable Speed Drives, pp. 500-505, London, UK, 2000.

[13] S. Bolognani, L. Tubiana, and M. Zigliotto, "Sensorless control of PM synchronous motors with non-sinusoidal back EMF for home appliance," in Proceedings of the IEEE International Electric Machines and Drives Conference (IEMDC '03), pp. 18821888, Madison, Wis, USA, June 2003.

[14] A. Lidozzi, L. Solero, F. Crescimbini, and R. Burgos, "Vector control of trapezoidal back-EMF PM machines using PseudoPark transformation," in Proceedings of the 39th IEEE Annual Power Electronics Specialists Conference (PESC '08), pp. 21672171, Rhodes, Greece, June 2008.

[15] C.-M. Ta, "Pseudo-vector control-An alternative approach for brushless DC motor drives," in Proceedings of the IEEE International Electric Machines and Drives Conference (IEMDC '11), pp. 1534-1539, May 2011.

[16] S. J. Park, H. W. Park, M. H. Lee, and F. Harashima, "A new approach for minimum-torque-ripple maximum-efficiency 
control of BLDC motor," IEEE Transactions on Industrial Electronics, vol. 47, no. 1, pp. 109-114, 2000.

[17] A. Oliveira, A. Monteiro, M. L. Aguiar, and D. P. Gonzaga, "Extended DQ transformation for vectorial control applications of non-sinusoidal permanent magnet synchronous machines," in Proceedings of the IEEE 36th Annual Power Electronics Specialists Conference, vol. 1, pp. 1807-1812, Recife, Brazil, 2005.

[18] P. Kshirsagar and R. Krishnan, "Efficiency improvement evaluation of non-sinusoidal back-EMF PMSM machines using field oriented current harmonic injection strategy," in Proceedings of the IEEE Energy Conversion Congress and Exposition (ECCE '10), pp. 471-478, Atlanta, Ga, USA, 2010.

[19] J. Y. Hung and Z. Ding, "Design of currents to reduce torque ripple in brushless permanent magnet motors," IEE Proceedings B: Electric Power Applications, vol. 140, no. 4, pp. 260-266, 1993.

[20] A. N'diaye, C. Espanet, and A. Miraoui, "Reduction of the torque ripples in brushless pm motors by optimization of the supplytheoretical method and experimental implementation," in Proceedings of the 2004 IEEE International Symposium on Industrial Electronics, IEEE-ISlE, pp. 1345-1350, May 2004.

[21] R. Bojoi, M. Pastorelli, J. Bottomley, P. Giangrande, and C. Gerada, "Sensorless control of PM motor drives-a technology status review," in Proceedings of the 1st Workshop on Electrical Machines Design Control and Diagnosis (WEMDCD '13), pp. 168-182, IEEE, Paris, France, March 2013.

[22] A. Halvaei Niasar, A. Vahedi, and H. Moghbelli, "Sensorless control of four-switch, brushless DC motor drive without phase shifter," IEEE Transactions on Power Electronics, vol. 23, no. 6, pp. 3079-3087, 2008.

[23] D. Yousfi, A. Halelfad, and M. El Kard, "Review and evaluation of some position and speed estimation methods for PMSM sensorless drives," in Proceedings of the International Conference on Multimedia Computing and Systems (ICMCS '09), pp. 409414, IEEE, Ouarzazate, Morocco, April 2009.

[24] Y. Zhao, C. Wei, Z. Zhang, and W. Qiao, "A Review on Position/ Speed Sensorless Control for Permanent-Magnet Synchronous Machine-Based Wind Energy Conversion Systems," IEEE Journal of Emerging and Selected Topics in Power Electronics, vol. 1, no. 4, pp. 203-216, 2013.

[25] G. R. A. Markadeh, S. I. Mousavi, S. Abazari, and A. Kargar, "Position sensorless direct torque control of BLDC motor," in Proceedings of the IEEE International Conference on Industrial Technology, IEEE (ICIT '08), pp. 1-6, April 2008.

[26] M. R. Feyzi, M. Shafiei, M. Bahrami Kouhshahi, and S. A. K. Mozaffari Niapour, "Position sensorless direct torque control of Brushless DC motor drives based on sliding mode observer using NSGA-II Algorithm optimization," in Proceedings of the 2nd Power Electronics, Drive Systems and Technologies Conference (PEDSTC '11), pp. 151-156, IEEE, Tehran, Iran, February 2011.

[27] Freescale Semiconductor, "Sensorless PMSM vector control with a sliding mode observer for compressors using MC56F8013," Document Number DRM099, 2008.

[28] A. Murray, M. Palma, and A. Husain, "Performance comparison of permanent magnet synchronous motors and controlled induction motors in washing machine applications using sensorless field oriented control," in Proceedings of the 2008 IEEE Industry Applications Society Annual Meeting (IAS '08), pp. 1-6, Edmonton, Canada, October 2008.

[29] Y. Shtessel, Ch. Edwards, L. Fridman, and A. Levant, Sliding Mode Control and Observation, Springer, Berlin, Germany, 2014. 


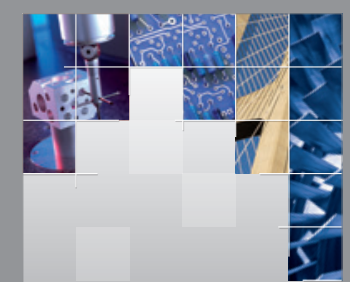

\section{Enfincering}
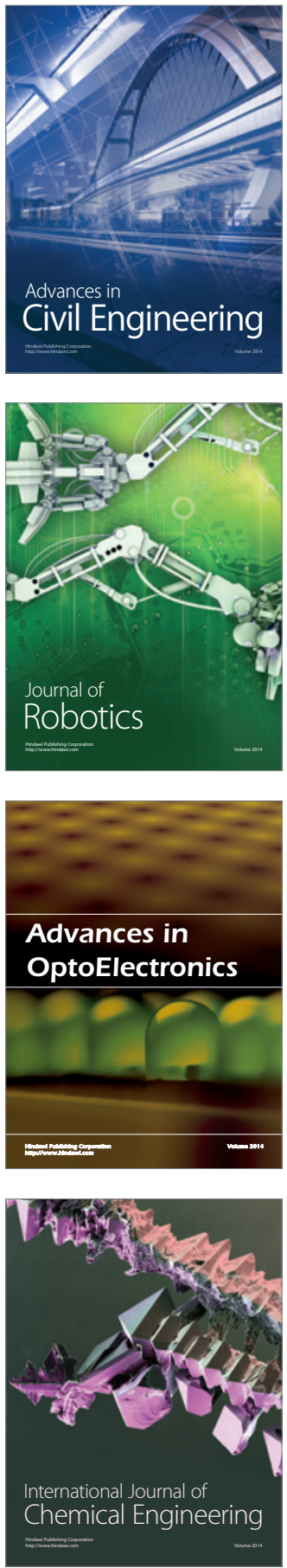

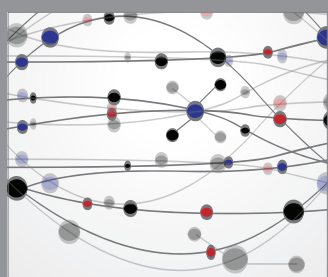

The Scientific World Journal

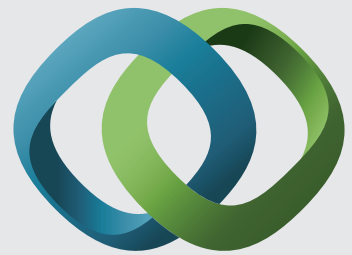

\section{Hindawi}

Submit your manuscripts at

http://www.hindawi.com
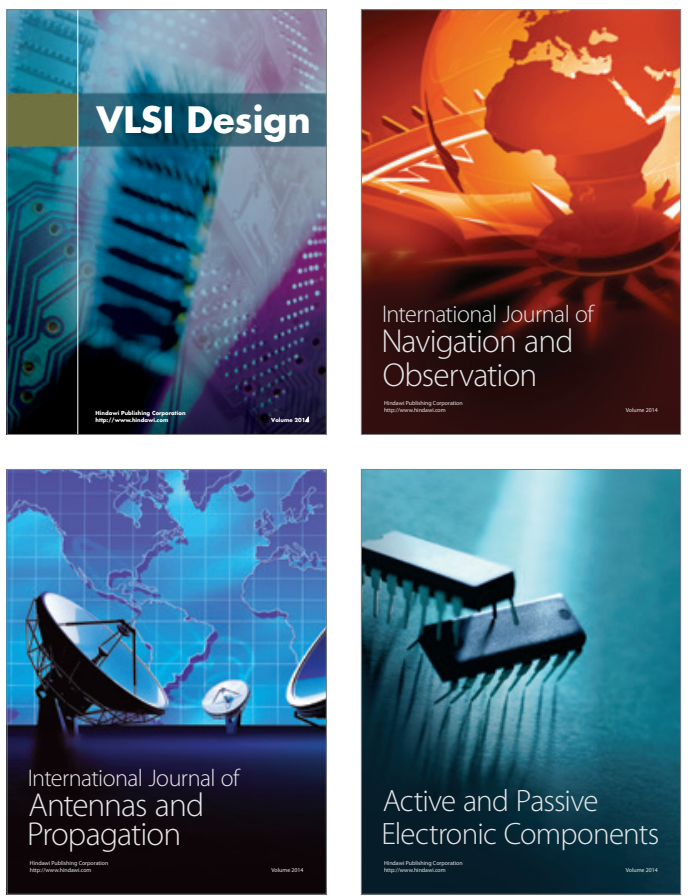
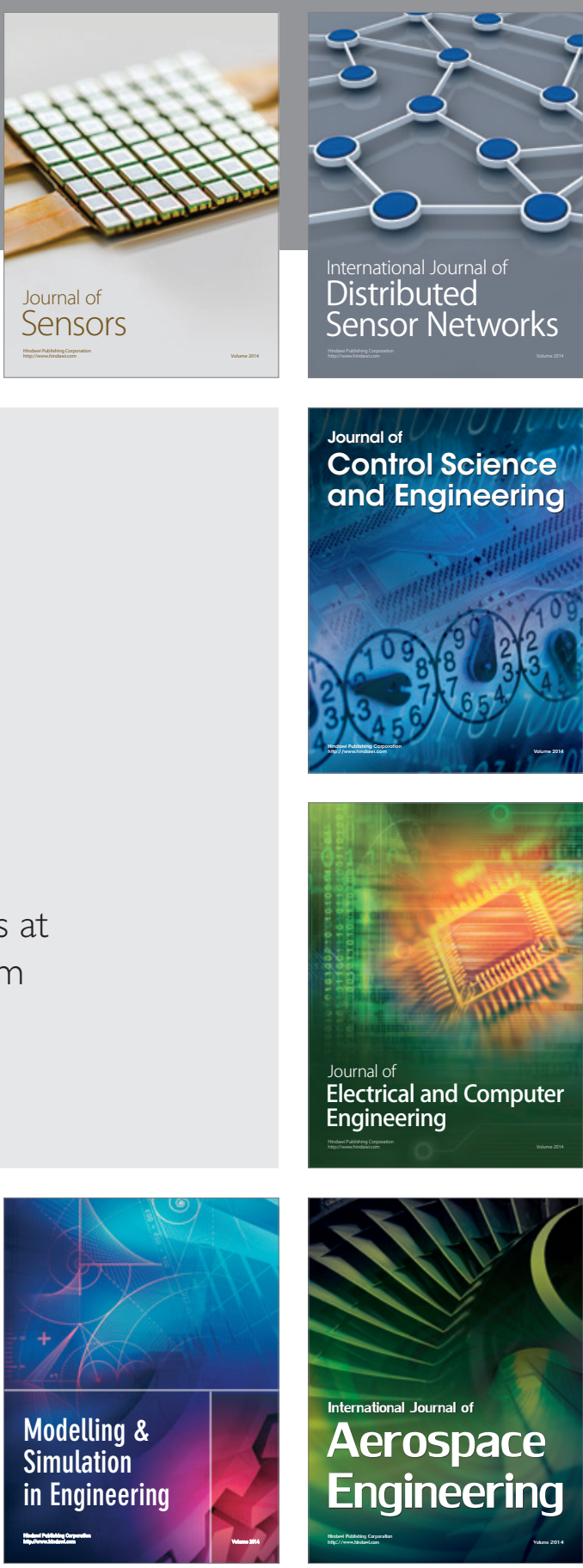

International Journal of

Distributed

Sensor Networks

Journal of

Control Science

and Engineering
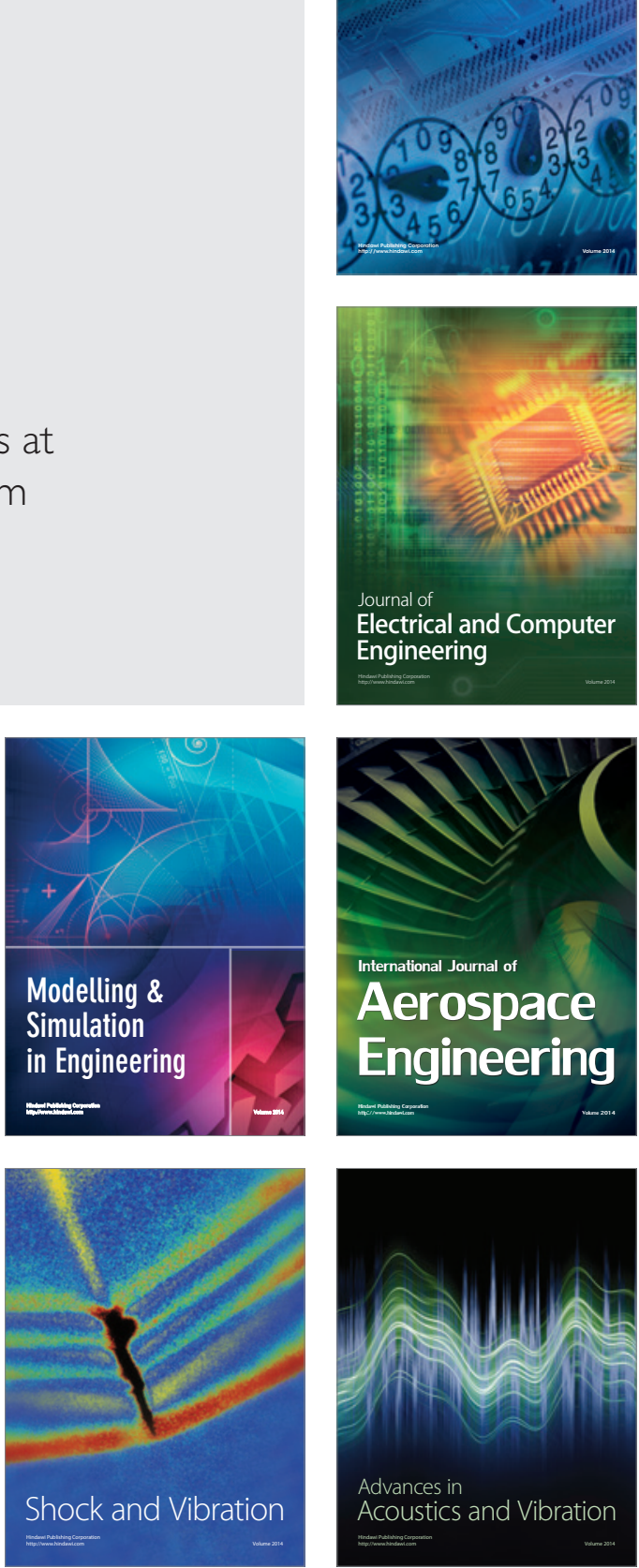